\title{
In vivo evolution of tumour cells after the generation of double-strand DNA breaks
}

\author{
H Mekid', O Tounekti ${ }^{2,6}$, A Spatz ${ }^{3}$, M Cemazar ${ }^{4}$, FZ El Kebir ${ }^{5}$ and LM Mir*,I \\ 'Vectorologie et transfert de gènes, UMR 8121 CNRS, Institut Gustave-Roussy, 39 rue C. Desmoulins, F-94805 Villejuif Cédex, France; ${ }^{2}$ Laboratoire \\ de Biochimie et Technobiologie, Faculté des Sciences de Tunis, Campus Universitaire, 1060 Tunis, Tunisia; ${ }^{3}$ Département d'Anatomie Pathologique, \\ Institut Gustave-Roussy, Villejuif 94805, France; ${ }^{4}$ Department of Tumor Biology, Institute of Oncology, Ljubljana, Slovenia; ${ }^{5}$ Laboratoire de Biologie du \\ Développement, Université d'Oran Es Sénia, 31000 Oran, Algeria
}

In vitro, the ratio of single- to double-strand DNA breaks (DSB) and their absolute values determine the cell death pathway. The consequences of the generation of various numbers of DSB generated in vivo in tumour cells have been analysed in two different experimental tumour models. Synchronisation of DSB generation and control of their number have been achieved using different doses of bleomycin (BLM) and tumour cell permeabilisation by means of locally delivered electric pulses. According to BLM dose, different cell death pathways are observed. At a low therapeutic dose, a mitotic cell death pathway is detected. It is characterised by the appearance of 'atypical mitosis', TUNEL and caspase-3 positive, $24 \mathrm{~h}$ after the treatment, and later by the presence of typical apoptotic figures, mainly TUNEL positive but caspase-3 negative. Caspase-3 is thus an early marker of apoptosis. Mitotic cell death is also followed by lymphocytic infiltration reaction. At high doses of BLM, pseudoapoptosis is detected within a few minutes after the treatment. These cell death pathways are discussed as a function of the number of DSB generated, by comparison with previous results obtained in vitro using BLM or ionising radiation.

British Journal of Cancer (2003) 88, I763-177I. doi:I0.1038/sj.bjc.6600959 www.bjcancer.com

(c) 2003 Cancer Research UK

Keywords: apoptosis; mitotic cell death; bleomycin; electrochemotherapy; electroporation; in vivo electropermeabilization

Cell death following exposure to toxic agents can occur through several routes, including apoptosis, extended or permanent cell cycle arrest, necrosis and 'mitotic catastrophe'. These various types of cell death display different morphological changes and biochemical characteristics. Such variations can result from differences between cell types and the mechanisms by which cell death is triggered.

At the cellular level, necrosis is characterised by an increased plasma membrane permeability, cell swelling, a decline in protein synthesis and autolysis (Wyllie et al, 1980; Schwartz and Osborne, 1993). It can be observed in solid tumours of mice treated with arsenic trioxide (Lew et al, 1999).

Apoptotic cell death plays a major role in the regulation of cell growth in multicellular organisms. It constitutes a systematic means of cell suicide during normal embryonic development and morphogenesis (von Wangenheim and Peterson, 1998), aging (Monti et al, 1992) or in response to pathogenic infections and other irreparable cell damage. Induction of apoptosis by anticancer drugs has been demonstrated using, for example, paclitaxel (Milross et al, 1996) or cisplatin (Trimmer and Essigmann, 1999). Recently, after cell treatment with ionising radiation, a

\footnotetext{
*Correspondence: Dr LM Mir; E-mail: luismin@igr.fr

${ }^{6}$ Current address: The Bloomfield Center for Research in Aging, Lady Davis Institute for Medical Research, Jewish General Hospital 3755 Chemin Cote Ste-Catherine, Montreal, Quebec, Canada H3T IE2. Received I October 2002; revised 6 March 2003; accepted 6 March 2003
}

'premitotic' and a 'postmitotic' apoptosis could be distinguished as a function of the morphological features of the treated cells (Shinomiya et al, 2000). Apoptosis requires the activation of proteases and endonucleases (Wyllie et al, 1984; Anderson et al, 1997). However, Tounekti et al (1993) showed that, in vitro, cell uptake of large quantities of BLM, a nonpermeant drug that generates double-strand DNA breaks (DSB), results in the very rapid generation of the apoptotic morphological changes, as well as in a DNA degradation similar to that observed in usual apoptosis. This evolution was termed pseudoapoptosis (Tounekti et al, 1993) because it is caused by the DSB generated by the bleomycin (BLM) and does not require induction of proteases nor endonucleases involved in typical apoptosis: BLM itself acts as a microendonuclease (Tounekti et al, 1995).

In vitro, mitotic cell death is a slow process in which cell metabolism remains functional for a period equivalent to more than two cell cycles, the cell death being noticeable only after the passage of the cell through one or more consecutive mitoses (Chang and Little, 1991; Radford, 1991). These mitoses are, nevertheless, aberrant and do not result in the formation of two daughter cells (Dewey et al, 1970; Joshi et al, 1982). This results in the generation of small abortive colonies by otherwise clonogenic cells. Mitotic cell death can be initiated by the generation of a few unrepaired DSB like those generated by small doses of ionising radiation or the internalisation of low amounts of radiomimetic drugs like BLM (Tounekti et al, 1993, 2001; Yanagihara et al, 1995).

Thus, in vitro, the number of DSB seems to determine the cell death pathway. Single-strand DNA breaks (SSB) in very large 
numbers also result in cell death (Yoshida et al, 1993; CohenJonathan et al, 1999). We also reported that not only the absolute numbers of DSB or SSB but also their ratio determine cell death pathway: true apoptosis, pseudoapoptosis or mitotic cell death (Tounekti et al, 2001).

On these basis, we decided to perform a systematic analysis of the consequences of the generation of different numbers of DSB in tumour cells in vivo. Control of DSB number, as well as synchronisation of the DSB generation was achieved using different doses of BLM and cell permeabilisation by means of locally delivered electric pulses (EPs). Indeed, (a) external electric fields generate changes in the transmembrane voltage and, under appropriate conditions, provoke the transient and reversible permeabilisation of the cells, in vitro as well as in vivo and (b) BLM molecules do not diffuse through the plasma membrane and they enter only at the time of the cell electropermeabilisation, in amounts proportional to the external concentration at the moment of EP. Moreover, permeabilising EP can be applied locally in vivo on tumour nodules: the huge increase in the antitumour effectiveness of BLM achieved by the increase in BLM uptake is the basis of electrochemotherapy (ECT), a new way to treat solid tumours that is already under clinical evaluation (Domenge et al, 1996; Mir et al, 1998; Gehl and Geertsen, 2000; Rodriguez-Cuevas et al, 2001; Rols et al, 2002). Therefore, it seemed possible to study in vivo the cell death pathway caused by different amounts of DSB using these experimental conditions. Indeed, in ECT, as performed in our preclinical and clinical studies, EPs alone are not toxic and the toxicity observed is actually the toxicity caused by the facilitated uptake of BLM.

\section{MATERIALS AND METHODS}

\section{Tumour cells culture and tumour production}

The LPB cell line, a methylcholanthrene-induced C57Bl/6 mouse sarcoma cell line (Belehradek et al, 1972), and the B16 F0 melanoma cells (ATCC CRL 6322) were cultured using classical procedures and minimum essential medium culture medium (Gibco BRL, Cergy-Pontoise, France) supplemented with $100 \mathrm{U} \mathrm{ml}^{-1}$ penicillin, $100 \mathrm{mg} \mathrm{ml}^{-1}$ streptomycin (Sarbach, France) and $8 \%$ fetal calf serum (Gibco). These two cell lines had been previously used in the laboratory in preclinical trials of the ECT (Mir et al, 1991, 1992; Sersa et al, 1994) as well as for analysing in vivo cell electrofusion (Mekid and Mir, 2000). C57Bl/6 female mice, 6-8 weeks old, were inoculated subcutaneously in the left flank with $1 \times 10^{6}$ to $1.2 \times 10^{6}$ syngeneic LPB cells or B16 cells, producing tumours $6-7 \mathrm{~mm}$ of diameter 9 days later. Mice were anaesthetised using a mixture of xylazine $12.5 \mathrm{mg} \mathrm{kg}^{-1}$ (Bayer Pharma, Puteaux, France) and ketamine $125 \mathrm{mg} \mathrm{kg}^{-1}$ (Parke Davis, Courbevoie, France). Animals were housed and handled according to the recommended guidelines (Workman et al, 1998). They were humanely killed by $\mathrm{CO}_{2}$ inhalation.

\section{Tumour treatment}

Bleomycin (Roger Bellon, Neuilly, France) was dissolved in sterile $0.9 \%$. $\mathrm{NaCl}$, aliquoted and stored at $-20^{\circ} \mathrm{C}$. At $4 \mathrm{~min}$ before $\mathrm{EP}$ delivery, BLM was injected in the retro-orbitary sinus at a dose of either $10 \mu \mathrm{g}, 100 \mu \mathrm{g}$ or $1 \mathrm{mg}$ in $100 \mu \mathrm{l} \mathrm{NaCl}$, per mouse, (approximately $0.5,5$ or $50 \mathrm{mg} \mathrm{kg}^{-1}$ ).

Tumour electropermeabilisation was performed as previously described (Mir et al, 1991). Stainless-steel external plate electrodes were placed on both sides of the protruding tumour, contact with skin was ensured by electrocardiography paste. Square-wave EPs (eight pulses of $100 \mu$ s delivered at a frequency of $1 \mathrm{~Hz}$ ) were generated by a PS15 electropulsator (Jouan, St Herblain, France) and controlled through a VC-6025 oscilloscope (Hitachi, Japan).
For $1350 \mathrm{~V} \mathrm{~cm}^{-1}$ pulses, $800 \mathrm{~V}$ was applied between two parallel electrodes $10 \mathrm{~mm}$ large and $6 \mathrm{~mm}$ apart. It was already known that these electrical parameters allow for the in vivo reversible electropermeabilisation of almost of cells in the LPB and B16F0 tumours since the administration of these EPs alone, without BLM, (like the administration of the BLM alone, with no EP), caused no statistically significant tumour growth delay (with respect to the control untreated tumours), while the concomitant administration of these EPs with BLM resulted in the achievement of complete regressions and even of cures (Mir et al, 1991, 1992, 1996; Sersa et al, 1994; Mekid and Mir, 2000). Then, mice were returned to their cages for different periods (between 1 and $100 \mathrm{~h}$ ) and killed to remove the tumours for histological processing. Three mice (i.e. three independent tumours) were used for each experimental condition.

\section{Histological procedures}

Tumours were fixed in AFA (75\% ethanol, 5\% acetic acid and 2\% of formaldehyde $40 \%$ ) for $24 \mathrm{~h}$, dehydrated and included in paraffin. Slices of $5 \mu \mathrm{m}$ were prepared using a Reichert-Jung 2030 microtome (Microm-Zeiss, Jena, Germany). Then slides were rehydrated and stained with HES (hemalun, $0.2 \%$; eosin, $0.3 \%$, saffron, 5\%). Alternatively, rehydrated slides were washed in phosphate-buffered saline (PBS; $50 \mathrm{mM} \mathrm{Na}_{2} \mathrm{HPO}_{4}, 50 \mathrm{~mm} \mathrm{NaH} \mathrm{PO}_{4}$ and $200 \mathrm{~mm} \mathrm{NaCl}, \mathrm{pH} 7.4$ ) and stained with $3 \mu \mathrm{M}$ propidium iodide (PI) (Sigma, La Verpillière, France).

\section{Immunohistochemical cell death determinations}

Apoptosis-specific staining (based on free DSB extremities labelling) was performed using the In-situ-Cell-Detection Kit, either alkaline phosphatase (AP) or fluorescein (Roche Molecular Biochemical, France). Deparaffinated slides were washed in PBS, digested with $20 \mu \mathrm{g} \mathrm{ml}^{-1}$ Proteinase $\mathrm{K}$ (Sigma) and processed according to the manufacturer's instructions. Briefly, free $3^{\prime}-\mathrm{OH}$ termini were labelled with fluorescein isothiocyanate (FITC)labelled deoxyuridine using the terminal transferase enzyme and detected either by fluorescence microscopy or with an AP-coupled anti-fluorescein antibody, and the subsequent incubation with fast red substrate.

The implication of a caspase-dependent cell death pathway was studied using an anti-activated caspase- 3 antibody (Pharmingen, San Diego, USA) (Hadjiloucas et al, 2001). Slices were deparaffinated, treated in a microwave oven and incubated overnight at $4{ }^{\circ} \mathrm{C}$ in the presence of the $1: 500$ diluted antibody. The positive cells were revealed using an appropriate Power Vision Detection AP System (ImmunoVision Technologies, Dalycity, CA, USA) and analysed using a Leica DMRB light microscope (Leitz, Wetzlar, Germany).

\section{Electron microscopy}

The treated tumours were fixed with phosphate-buffered glutaraldehyde (Ladd Research Industries, England), postfixed with osmium tetroxide (Prolabo, France) and then dehydrated, processed, sliced and observed under a Zeiss 902 electron microscope.

\section{Microscopic slides examination}

Slides were examined under a Leica DMRB microscope equipped with an automatic photographic device. For fluorescence microscopy, the filter set for rhodamine detection was used to observe the PI-stained slices and the filter set for FITC detection to observe the apoptotic cells stained with the In-situ-Cell-Detection Fluorescein Kit. 
For each experimental condition, three mice were treated, and from each mouse, three HES-stained tumour slides were prepared. In all the cases, the entire slide was examined to detect all the types of cell patterns generated under each experimental condition. To determine the percentages of each cell pattern, all the cells from four randomly chosen fields of non-necrotic areas of each of the three slices prepared from each tumour were counted. The percentages of each cell pattern were calculated with respect to the total number of cells counted. On the average, 1500 cells were counted for each experimental condition.

\section{Statistical analysis}

All data are presented as means and standard deviations. Statistical analysis of the significance of the difference between the controls and the groups treated under the various experimental conditions was performed using Student's $t$-test.

\section{RESULTS}

Based on their morphology, tumour cells were classified into four categories: (a) cells with normal morphology and size, (b) atypical cells (see below), (c) apoptotic cells showing classical DNA condensation and (d) typical mitotic cells. The percentages of cells in each category were determined at various times after tumour exposure to EP in BLM-injected mice (i.e. after ECT). Morphological estimation of apoptosis was based on cell characteristics, such as marked condensation and marginalisation of the chromatin or formation of apoptotic bodies. Atypical cells were the ones showing extended and intense pycnosis, where it was impossible to distinguish between the nucleus and cytoplasm. Under some conditions, further described, cells with normal morphology but larger than those found in untreated tumours were also observed. Even though their apparent diameter could reach twice the apparent diameter of the normal cells, they were still counted as cells with normal morphology.

\section{Histological characteristics of the untreated tumours}

As revealed by HES staining, LPB fibrosarcoma was a tissue in which many mitosis were detectable (Figure 1A, B). Cells were densely packed and the membrane separating each individual cell was not always distinguishable. In the absolute control $5 \pm 0.3 \%$ of cells were in mitosis (Figure $2 \mathrm{I}$ ), $2.7 \pm 0.1 \%$ in the EP alone control and $3 \pm 0.2 \%$ in the BLM alone control (the data concerning the EP alone control and the BLM alone control are not shown in the figures; they were obtained on tumours removed and fixed $5 \mathrm{~h}$ after the respective treatment). The percentages of typical apoptotic figures (Figure 1B) were $3.1 \pm 0.9 \%$ in the absolute control (Figure $2 \mathrm{II}), 2.7 \pm 0.7 \%$ in the EP and $2.5 \pm 0.5 \%$ in the BLM controls. Atypical figures (Figure 1A) were regularly found in all LPB control tumours: $4.3 \pm 1.8 \%$ in the absolute control (Figure 2III), $5.5 \pm 0.7 \%$ in the EP and $5 \pm 0.7 \%$ in the BLM controls.

In the B16 tumours, the membrane limiting each individual cell was clearly visible (Figure 1C, D). The nuclei in the untreated control tumours displayed a relatively regular size and were usually located in the centre of the tumour cells. In absolute control, $2.3 \pm 0.1 \%$ of the cells were in mitosis (Figures $1 \mathrm{C}$ and $2 \mathrm{I}$ ), $4.0 \pm 0.1 \%$ in the EP alone and $1.3 \pm 0.1 \%$ in the BLM alone controls. The percentages of typical apoptotic figures were $2.0 \pm 0.2 \%$ in the absolute control (Figure 2II), $3.5 \pm 0.3 \%$ in the $\mathrm{EP}$ and $2.6 \pm 0.5 \%$ in the BLM controls. Atypical figures (Figure 1D) were regularly found also in all the $\mathrm{B} 16 \mathrm{~F} 0$ control tumours $(2.4 \pm 0.1 \%$ in the absolute control (Figure $2 \mathrm{III}), 4.0 \pm 0.6 \%$ in the $\mathrm{EP}$ and $7.0 \pm 0.7 \%$ in the BLM controls).

No immune cell infiltrated the LPB tumour tissue in the absence of treatment. Some lymphocytes were detected at the periphery of
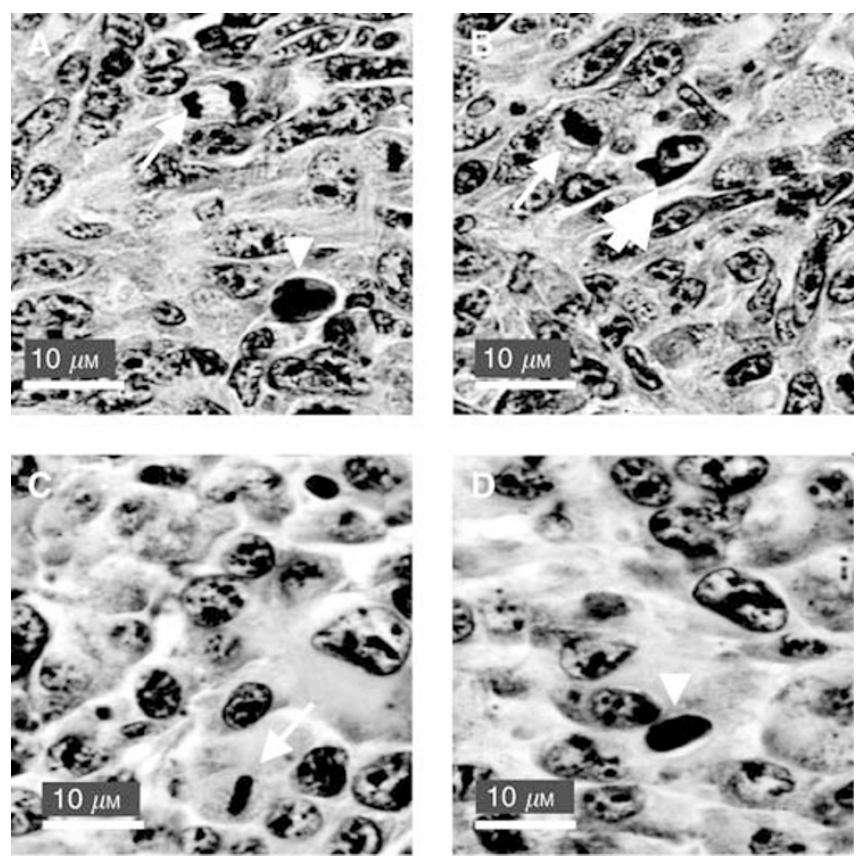

Figure I Histological characteristics of the untreated murine fibrosarcoma tumour LPB (A and B) and murine melanoma tumour BI 6FO (C and D). Small arrows: mitotic cells; large arrows: apoptotic cells; arrowheads: atypical cells.

the tumour only. In the B16 melanoma, spontaneous necrosis areas were found even in small-untreated tumours. In these areas, immune cells could be easily observed (data not shown).

\section{Changes in the fraction of cells in mitosis after in vivo exposure to BLM and EP}

Using a high dose of BLM (1 mg per mouse) After the treatment, a rapid decrease in the fraction of cells in mitosis was observed in both tumours, and after $3 \mathrm{~h}$ mitoses became almost undetectable (Figure 2IA). At $5 \mathrm{~min}$ after the treatment of LPB or B16F0, the percentage of mitosis decreased to approximately $40-45 \%$ of controls. These percentages continued to decline significantly in the tumours at $1 \mathrm{~h}$, and later, after the ECT (Figure 2IA). Interestingly, the existence of abnormal mitosis was detected in HES-stained slices 10-20 min after the treatment. At $30 \mathrm{~min}$, all the mitoses still visible displayed aberrant figures. No mitosis was observed thereafter.

Using a low dose of BLM (10 $\mu \mathrm{g}$ per mouse) A similar drastic reduction of the fraction of cells in mitosis was observed in both the tumours (Figure 2IB). The percentage of mitosis in LPB and $\mathrm{B} 16 \mathrm{~F} 0$ was found to be reduced at $5 \mathrm{~h}$ after the treatment and remained at this low value until $100 \mathrm{~h}$ in the case of the LPB tumour. In the case of $\mathrm{B} 16 \mathrm{~F} 0$, the decrease was smaller at $5 \mathrm{~h}$ than the decrease observed in LPB, and some cells in mitosis were still detected at $30 \mathrm{~h}$. However, these percentages were lower than in untreated controls (Figure 2IB).

\section{Changes in the fraction of apoptotic cells}

Using $1 \mathrm{mg}$ BLM per mouse In the LPB tumours, cell morphology started to change in certain areas of the tumours very shortly after the EP delivery. As revealed by the HES staining, as soon as $5 \mathrm{~min}$ after the treatment, $20 \%$ of the observed nuclei displayed condensation of chromatin that evoked apoptosis. At $10 \mathrm{~min}$, the 

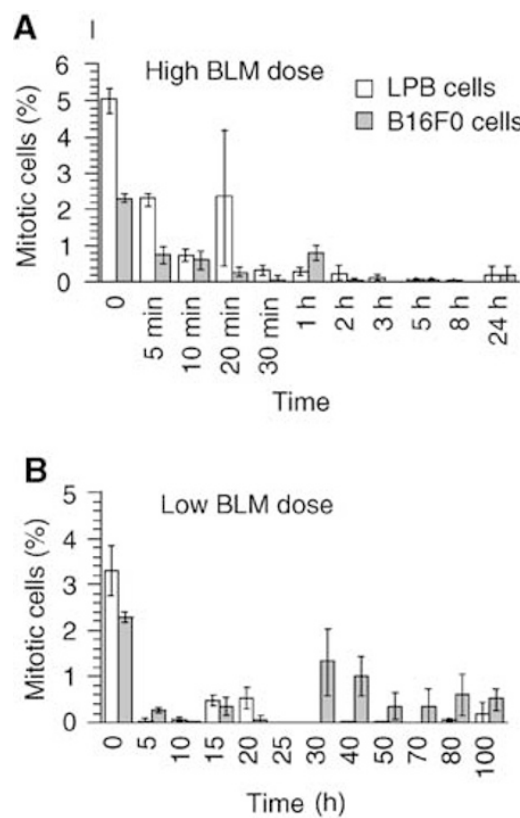
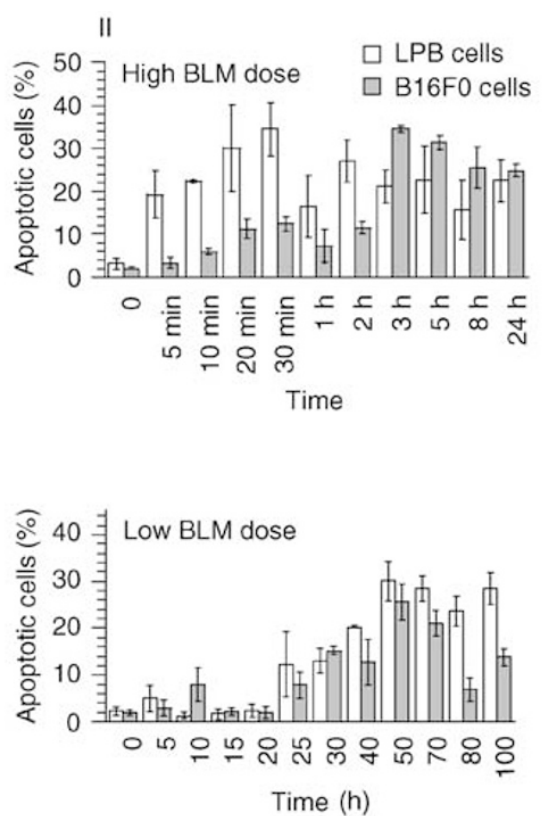
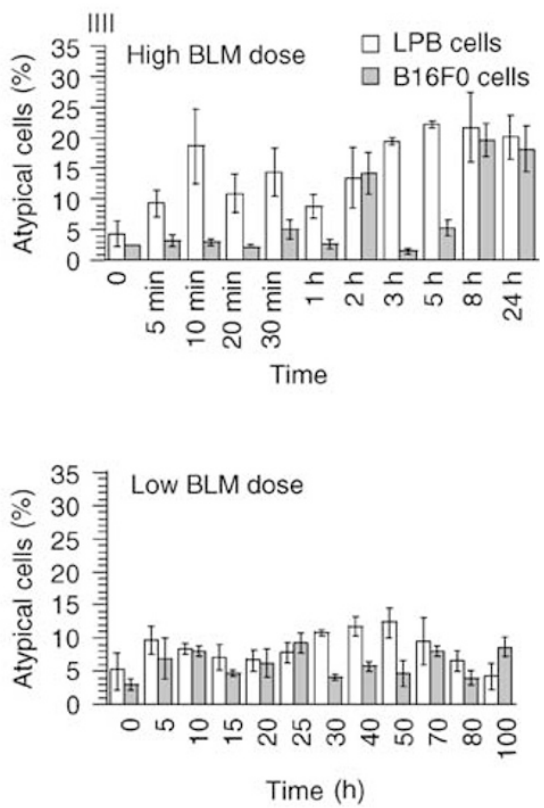

Figure 2 Kinetics of the fraction of (I) mitotic cells, (II) apoptotic cells and (III) atypical cells in LPB and BI 6F0 tumours after ECT using I mg BLM (panels A) or $10 \mu \mathrm{g}$ BLM (panels B). Statistical analysis: all groups were compared to the respective controls by means of Student's t-test. All groups were significantly different from the controls (at least $P<0.05$ ) except in panels IIA LPB (at I and $8 \mathrm{~h}$ ), IIA BI 6FO (at $5 \mathrm{~min}$ and I $\mathrm{h}$ ), IIB LPB (before $20 \mathrm{~h}$ ), IIBB BI6F0 before $25 \mathrm{~h}$, IIIA BI6FO (at $5 \mathrm{~min}$ and I h), IIIA LPB (20 min, I h and $2 \mathrm{~h}$ ), IIIB BI6FO at 50 h and IIIB LPB at I5, 20, 25 and after $70 \mathrm{~h}$.

percentage was 10 -fold larger $(22.4 \pm 0.3 \%)$ than that observed in control tumours. A maximum of $34.5 \pm 6.3 \%$ of nuclei with condensed and margined chromatin was reached at $30 \mathrm{~min}$ (Figure 2IIA).

Changes were more pronounced in certain areas of the tumours slices where all the cells displayed marked condensation of the chromatin, and sometimes already the appearance of apoptotic bodies (Figure 3A, C). In order to clearly visualise the condensation and marginalisation of chromatin in nuclei and to confirm these data, we also stained some slices with PI (data not shown).

In the $\mathrm{B} 16 \mathrm{~F} 0$ tumours treated under the same conditions, a massive percentage of apoptotic cells were also observed in some areas of the tumour (Figure 3B, D). However, the increase in apoptotic cells was more progressive (Figure 2IIA) since a highly significant five-fold increase was observed only at $20 \mathrm{~min}$ $(11.3 \pm 2.3 \%)$. For both LPB and B16F0 tumours, a decrease in the fraction of the apoptotic cells was observed at $1 \mathrm{~h}$ after the treatment, followed, respectively at 2 and at $3 \mathrm{~h}$, by an ulterior increase (Figure 2IIA).

Using $10 \mu \mathrm{g}$ BLM per mouse In the presence of a low amount of BLM, it was possible to subdivide the evolution of the fraction of apoptotic cells into two intervals (Figure 2IIB), before and after $25 \mathrm{~h}$ after the ECT. In the interval of $0-25 \mathrm{~h}$, the percentage of apoptotic cells was similar to that of the control tumours (around $2 \%$ ), although a significant four-fold increase in apoptotic cells was observed in the B16F0 population at $10 \mathrm{~h}$. In both tumours from $25 \mathrm{~h}$ until $100 \mathrm{~h}$, the percentage of apoptotic cells progressively increased up to a maximum observed at $50 \mathrm{~h}$ (respectively $30.1 \%$ for the $\mathrm{LPB}$ and $25.6 \%$ for the $\mathrm{B} 16 \mathrm{~F} 0$ tumours) (Figure $2 \mathrm{IIB}$ and 3E, F).

In the B16F0 melanoma tissue, it was necessary to distinguish between the areas with individual cells and those with large polykaryotic cells resulting from the in vivo electrofusion of B16F0 cells (Mekid and Mir, 2000). In the areas containing individual unfused cells, no change in the percentage of apoptotic cells was found at any time after the treatment between the treated and controls. On the contrary, in the areas displaying fused cells, the percentage of apoptotic cells increased significantly from $25 \mathrm{~h}$ after the treatment until $100 \mathrm{~h}$. At $50 \mathrm{~h}, 92.8 \%$ of the whole of the apoptotic nuclei were found in the fused cells, and $96.4 \%$ of the nuclei in the fused cells were apoptotic. (data not shown in the figure).

Thus, our results show that apoptotic cells can be found either very rapidly after the treatment in the presence of a high amount of $\mathrm{BLM}$ or after more than $25 \mathrm{~h}$ in the presence of a low amount of BLM.

\section{Changes in the fraction of atypical cells}

Using $1 \mathrm{mg}$ BLM per mouse A net increase in the fraction of atypical cells (two-fold with respect to the untreated tumours) was found in LPB fibrosarcoma $5 \mathrm{~min}$ after the treatment. At $10 \mathrm{~min}$, the increase was approximately four times. This increase persisted at $3 \mathrm{~h}$ and later on (at 5, 8 and $24 \mathrm{~h}$ ) (Figure 2IIIA). Contrary to LPB fibrosarcoma, the percentage of atypical cells became larger (seven to nine times higher) than that observed in untreated control tumours only at $2 \mathrm{~h}$ and then at 8 and $24 \mathrm{~h}$, while in the interval between 0 and $1 \mathrm{~h}$, values were close to that of control B16F0 tumours (Figure 2IIIA).

Using $10 \mu \mathrm{g}$ BLM per mouse The rate of atypical cells in LPB tumours was slightly increased at all times except at $100 \mathrm{~h}$. A significant increase was found at early times (up to $5 \mathrm{~h}$ ) as well as at later times $(30-50 \mathrm{~h})$. This evolution was very different compared to the changes in apoptotic cells in the same fibrosarcoma (Figure 2IIB, IIIB). Contrary to LPB fibrosarcoma, the trend of the changes in the percentage of atypical cells in B16F0 tumours was not clear. Variations were observed from each time point to the next one. Variations with respect to control values never exceeded three times (Figure 2IIIB). 

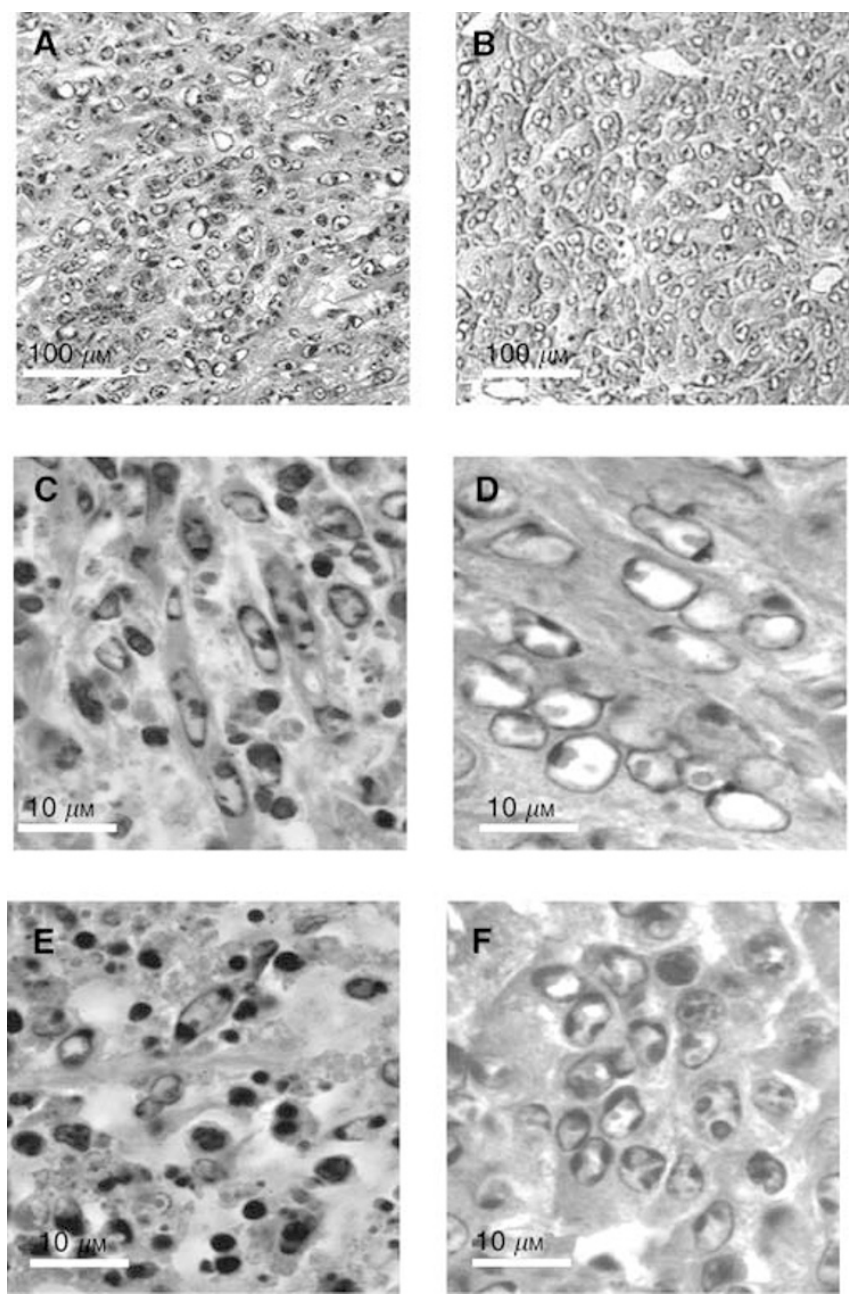

Figure 3 Histological changes observed in tumours removed $30 \mathrm{~min}$ after ECT using I mg BLM (A-D) and in tumours removed $50 \mathrm{~h}$ after ECT using $10 \mu \mathrm{g}$ BLM (E and $\mathbf{F}) ;(\mathbf{A}, \mathbf{C}$ and $\mathbf{E})$ : LPB tumours; (B, D and $\mathbf{F})$ : BI6F0 tumours.

\section{Other histological changes observed}

Changes in tumour cell size At the high dose, no change in cell size was observed: both the atypical and the apoptotic nuclear changes were detected in cells displaying the same apparent diameter than in the untreated tumours. At the low dose, for the first $25 \mathrm{~h}$ following the EP, the cells showing a normal nucleus became progressively larger than in untreated tumours. At the end of this period, the apparent diameter of the nuclei could be twice as large as that of the normal cells. This evolution was observed in both LPB and B16F0 tumours treated using $10 \mu \mathrm{g}$ BLM (data not shown). As a consequence, atypical cells displayed an apparent diameter larger than that of the control tumour cells, while apoptotic cells displayed a diameter lower than that of the atypical cells but still similar to that of the cells in control tumours.

Changes in immune cell distribution After ECT using $1 \mathrm{mg}$ BLM, no change in the distribution of the immune cells infiltrate was observed. Using $10 \mu \mathrm{g} \mathrm{BLM}$, it was possible to detect a large infiltration of the LPB tumours by lymphocytes from $25 \mathrm{~h}$ after the EP delivery. At longer times, such as 50 or $70 \mathrm{~h}$, a large number of infiltrating lymphocytes were present in all the parts of the LPB tumours, but with a higher density where a large fraction of apoptotic cells was also present. In the case of the B16F0 tumours,
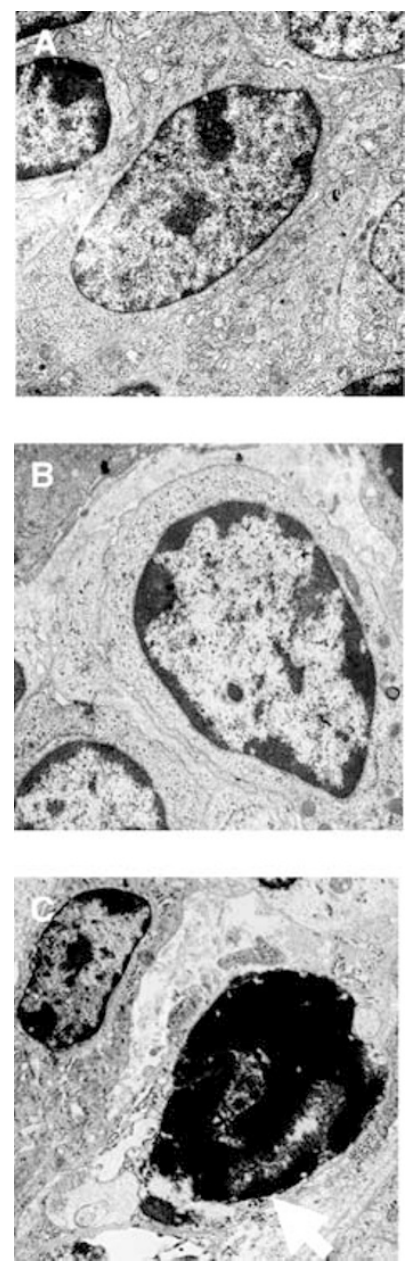

Figure 4 Electron microscopy images of LPB tumours treated by ECT: (A) untreated control fibrosarcoma; (B) typical apoptotic cell observed in tumours removed $30 \mathrm{~min}$ after ECT using I mg BLM; (C) atypical cell observed in tumours removed $25 \mathrm{~h}$ after ECT using $10 \mu \mathrm{g}$ BLM, the arrow indicating the double membrane; $\times 17500$

in which lymphocytes were already detectable in the spontaneous necrosis area controls, no major change could be noticed at any time.

\section{Electron microscopy}

Slices of B16F0 tumours treated with $1 \mathrm{mg}$ of BLM and removed at $10 \mathrm{~min}, 15 \mathrm{~min}$ and $1 \mathrm{~h}$ were analysed to verify that the rapid change in chromatin morphology was similar to that observed when apoptosis occurred spontaneously or when it was induced by other known agents. Changes in the nuclei were actually typical of apoptotic cells (Figure 4A, B): the chromatin was condensed at the limit of the nucleus, forming clumps pressed against the nuclear envelope, and the cytoplasm was dense. Moreover, at $1 \mathrm{~h}$, mitochondria displayed autolytic changes (data not shown).

We also checked whether the atypical cells detected under light microscopy showed ultrastructural modifications similar to or different from those of the apoptotic cells. The chromatin fragments that are observed in atypical cells can be surrounded by a double membrane (Figure 4C) as already found by Dini et al (1996), who treated the cells using $\mathrm{H}_{2} \mathrm{O}_{2}$ and described the images seen in the atypical cells as a result of perturbations in the condensation of the mitotic chromosomes. 

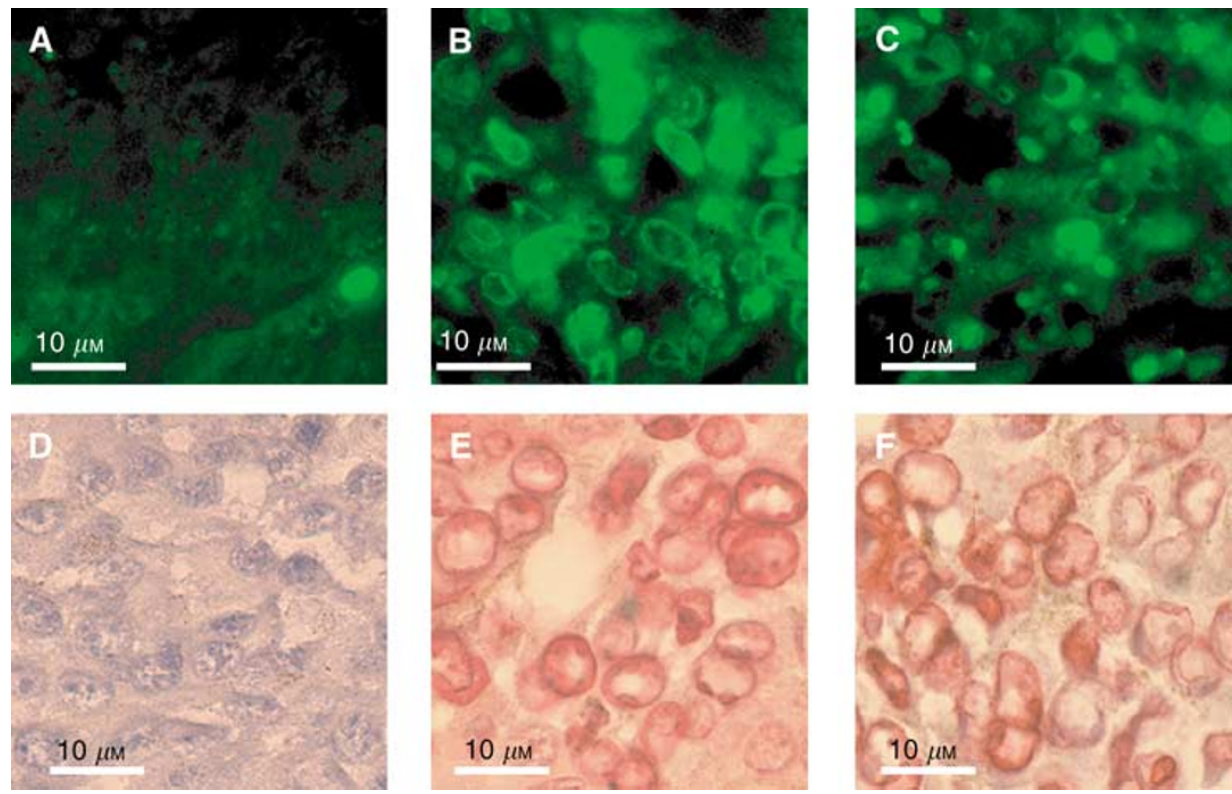

Figure 5 Immunohistochemical detection of DNA fragmentation in tumour cells. Fluorescein detection $(\mathbf{A}-\mathbf{C})$; alkaline phosphatase detection (D-F); $(\mathbf{A}-\mathbf{C})$ : LPB fibrosarcoma; (D-F): BI6F0 melanoma; (A and D): stained untreated controls; (B and $\mathbf{E})$ : staining of tumours removed 30 min after ECT using I $\mathrm{mg}$ BLM; $(\mathbf{C}$ and $\mathbf{F})$ : staining of tumours removed $50 \mathrm{~h}$ after ECT using $10 \mu \mathrm{g}$ BLM.

\section{Immunohistochemistry}

TUNEL-specific assay for apoptotic cells Nuclei presenting chromatin condensation as well as atypical cells were found positive with the TUNEL assay demonstrating that chromatin was fragmented in these cells (Figure 5). The TUNEL staining was also applied to LPB cells electropermeabilised in vitro in the presence of high external concentrations of BLM (from 10 to $66 \mu \mathrm{M}$ ) that resulted in pseudoapoptosis. A progressive increase in the number of positive cells and in the intensity of the staining was found with increasing external concentrations of BLM (data not shown). Therefore, the TUNEL assay was able to label both the real apoptotic cells and the pseudoapoptotic cells generated by the introduction, in vivo, of large amounts of BLM into the tumour cells. At a low dose of BLM, cells were TUNEL negative for at least $15 \mathrm{~h}$ suggesting strongly that the number of DSB directly generated by the low BLM dose was very low.

Caspase-3 staining In the absence of treatment, a large number of the atypical cells found in the LPB or B16 tumours were caspase- 3 positive, while only a few of the apoptotic cells were caspase-3 positive.

After ECT of LPB tumours using $1 \mathrm{mg}$ BLM, a large number of cells very rapidly displayed apoptotic characteristics (Figure 3), whereas the anticaspase- 3 staining was restrained only to a very few apoptotic or atypical cells, confirming the pseudoapoptotic evolution suggested by the morphological analysis. At $5 \mathrm{~h}$, when the percentage of LPB atypical cells was very high, the number of stained cells was also high, involving a large fraction of these atypical cells (Figure 6).

After ECT with $10 \mu \mathrm{g}$ of BLM, caspase-3 staining was observed only after $25 \mathrm{~h}$ in most of the atypical cells, as well as a few of the apoptotic cells. All the large cells were caspase-3 positive and their staining was more intense than the staining observed after a high dose of BLM or in untreated controls. In additional experiments (data not shown), slides of tumours treated with an intermediary dose of BLM (100 $\mu \mathrm{g}$ per injection) were also examined. Their histological analysis revealed a large number of atypical cells that were mainly caspase- 3 positive, even though, again, all the atypical or condensed cells were not stained.

\section{DISCUSSION}

Two important findings emerged from these results. First, ECT with BLM immediately induces in vivo a large decrease of the number of cells in mitosis and secondly, BLM induces two distinct types of tumour cell death, as a function of the BLM dose injected before the ECT. These observations can be related to previous data using cells in culture. First, in vitro, no mitosis is detectable after cell electropermeabilisation in the presence of BLM: cells accumulate in $\mathrm{G}_{2} / \mathrm{M}$ if low concentrations of BLM are used, while pseudoapoptotic figures are generated in the presence of large BLM concentrations. Secondly, in vitro as well (Tounekti et al, 1993), after cell electropermeabilisation in the presence of different doses of BLM, we observed two very different groups of morphological features that, as further discussed here, allow to conclude that, both in vitro and in vivo, tumour cells can die either through a mitotic cell death process at low BLM doses or by pseudoapoptosis at high doses. This BLM-dose-dependent cell death is present in the two tumours studied, which were chosen for this study because both tumours grow in the $\mathrm{C} 57 \mathrm{Bl} / 6$ mice, keeping homogeneous the host reactions, and because the same pulse parameters are necessary to achieve the electropermeabilisation of almost all the cells in the tumour. Interestingly, these two tumours differ by their histological origins, spontaneous tendency to necrose and spontaneous lymphocytic infiltrate. Moreover, they respond differently to the EP (Mekid and Mir, 2000).

\section{Evolution of the number of 'apoptotic figures' and 'atypical figures', and origin of these figures}

Besides the decrease in the number of mitotic figures, our new in vivo data show that, at low and high BLM doses, there is a large increase of two types of figures that we classified as 'apoptotic figures' and 'atypical figures' (already present in low percentages in the untreated tumours). For the LPB and B16F0 apoptotic cells, similar changes were observed, except that, at the high BLM dose, the increase in the number of apoptotic cells was detected earlier in the LPB than in the B16F0 tumours. The atypical figures were previously analysed after in vitro cell treatment by $\mathrm{H}_{2} \mathrm{O}_{2}$ (Shacter et al, 2000): according to these authors, atypical figures correspond 

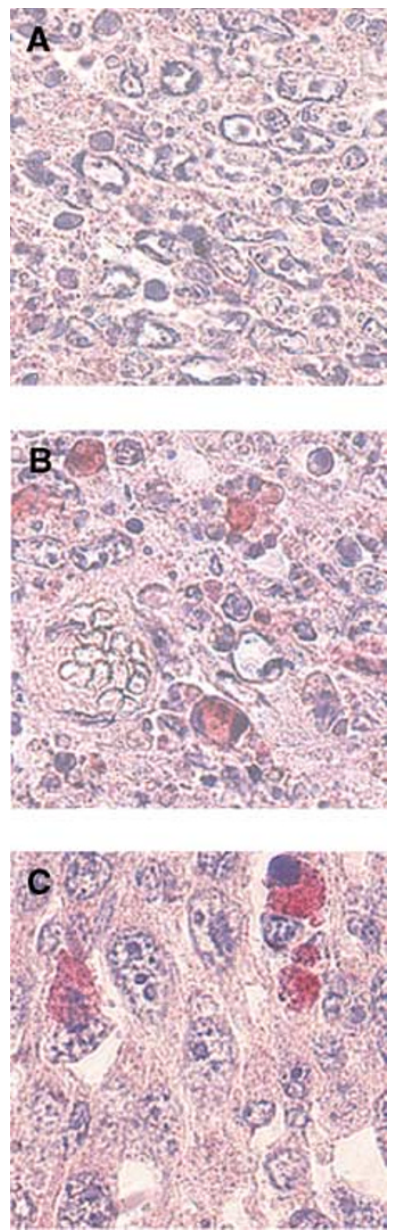

Figure 6 Immunohistochemical detection of activated caspase-3: (A and B): LPB tumour removed $5 \mathrm{~h}$ after ECT using I mg BLM; (C) LPB tumour removed $50 \mathrm{~h}$ after ECT using $10 \mu \mathrm{g}$ BLM.

to a delayed cell death and can be described as pycnotic/necrotic cells showing cytoplasmic swelling and mild pycnosis of the nucleus. On the one hand, after ECT, at the low BLM dose, the appearance kinetics of the atypical figures were similar for both the tumour types. They appeared after a long period $(25 \mathrm{~h})$, which is, nevertheless, much shorter than the in vivo generation time (Sersa et al, 1994). Since in the mean time the cells had become much larger, these atypical figures were mainly large cells. They represent a phase in the process of mitotic cell death, and as discussed below could be either a step before the appearance of the classical apoptotic figures or another step of the cells dying through the mitotic cell death pathway. On the other hand, at the high BLM dose, atypical figures appeared rapidly (in a few minutes in the LPB tumours, and at $2 \mathrm{~h}$ and then at $8 \mathrm{~h}$ in B16F0 tumours). Cells had no time to enlarge and did not differ in size from the untreated control cells. Thus, the origin of the atypical cells could be different, depending on the BLM dose.

The analysis of the atypical and the apoptotic cells shows that both are TUNEL positive. However, while most of the atypical cells were caspase- 3 positive, most of the apoptotic cells were not. These two types of figures could perhaps correspond to two different stages in a common apoptotic pathway (Hadjiloucas et al, 2001) or to two different apoptotic cell death pathways, one caspase-3 dependent and one not (Tauchi and Sawada, 1994; Yanagihara et al, 1995; Kolenko et al, 2000). These two pathways could result from differences in the cell cycle position of the cells at the time of their electropermeabilisation and, therefore, at the time of the DSB generation, or from a different number of BLM molecules internalised (thus of a different number of DSB). It is interesting to note that using low BLM doses, the number of DSB is low just after the ECT and cells remain negative to the TUNEL assay for several hours (the DSB directly generated by BLM are actually recognised by the TUNEL assay, as reported in the Results section). However, atypical cells (as well as apoptotic cells) are TUNEL positive, indicating that a cell process generating DSB apoptosis has been actually induced after the DNA damage provoked by the low amount of the BLM.

\section{In vivo BLM causes mitotic cell death or pseudoapoptosis}

Our data show that there are two cell death types observed after ECT, which can be related to the action of the BLM entering the cells in vivo in different amounts and thus to the generation of different numbers of DSB. The results can be compared to those found on cells in culture where it was easy to test a large number of different BLM concentrations. In vivo it is not easy to acquire the amount of data as it is in vitro, and only two different amounts of BLM (differing 100 times) injected to the mice were analysed in detail. An intermediary concentration, $100 \mu \mathrm{g}$ per mouse, was also tested (data not shown) and intermediary results were found in the time points examined confirming the dependence, discussed below, of the changes observed on the amount of injected BLM.

In vitro, in the presence of 10 or $100 \mu \mathrm{M}$ BLM (high doses), cells displayed a pseudoapoptotic evolution: all the apoptosis morphological and biochemical characteristics (Kerr and Searle, 1972) could be found, shortly after the ECT (as reported in the introductory section). In fact, the speed at which these changes were obtained was dependent on the BLM external concentration: the higher that concentration, and therefore the higher the amount of BLM internalised into the cells (Poddevin et al, 1991), the faster the changes observed (Tounekti et al, 1995). Thus in vivo, at the high BLM dose, the large numbers of rapidly appearing apoptotic figures could be the result of a pseudoapoptotic process. It is also interesting to note that, with the high BLM dose, the large amounts of apoptotic figures here reported at $30 \mathrm{~min}$ after ECT were, in fact, localised in defined areas of the tumours, where almost all the cells in that area displayed chromatin condensation. These areas were almost undetectable at $1 \mathrm{~h}$, may be because the apoptotic residues had been phagocytosed by the neighbouring live cells. At 2 or $3 \mathrm{~h}$, large areas comprising almost exclusively apoptotic figures were found again. This observation can be explained taken into account that (i) in vitro the speed at which chromatin condensation is detected in electropermeabilised cells exposed to high external BLM concentrations is dependent on the external concentration, (ii) the supply of BLM in the tumour is not homogeneous and very much related to the tumour vasculature and (iii) that the electric field distribution and thus cell electropermeabilisation is not totally homogeneous within the whole tumour. Thus, like in vitro, the larger the amount of BLM available and internalised, the faster the appearance of the apoptotic figures, suggesting that in vivo as well, a 'pseudoapoptosis' is the mechanism of cell death caused by the rapid uptake of large amounts of BLM.

For the low doses of BLM, the in vivo and in vitro evolutions are not identical. Indeed, in vitro, in the presence of 10 or $100 \mathrm{nM}$ BLM (low doses), the electropermeabilised cells died slowly through a process reminiscent of the mitotic cell death described after the in vitro treatment of cells by ionising radiation (Chang and Little, 1991; Radford, 1991). No mitosis was detectable for a period equivalent to a cell cycle after the BLM internalisation, resulting in the accumulation of the cells in $\mathrm{G}_{2}$. This blockage was followed by an abnormal mitosis that resulted in the appearance of only one, large, often binucleated cell that could still complete a second entire cell cycle (Tounekti et al, 1993). A second mitosis could 
sometimes be observed. Karyotypes were highly modified (Tounekti et al, 1993). Cell death, that is, the cessation of cell metabolism, and the disappearance of cell structure occurred by processes that could not be described. Indeed, in vitro, the experimental synchronisation of the mitotic cell death triggering obtained by the cell electropermeabilisation, which allowed the study of the initial steps of this pathway, could not be maintained to describe its final steps. We could not detect the appearance of the oligonucleosomal ladder, but this does not mean that no apoptosis could occur. In fact, we supposed that cells were dying because of necrosis (i.e. that cells swelled, lysed and released their content into the extracellular medium).

In vivo, at low BLM doses, cells present an evolution that, at the beginning, is reminiscent of the in vitro observations (transient mitosis disappearance). However, in vivo, the end point of this evolution seems to be typical and/or 'atypical' apoptosis. It cannot be totally excluded that the atypical cells could be the result of an 'atypical apoptosis'. However, in agreement with the conclusions of Hadjiloucas et al (2001), our results suggest that in vivo the atypical cells, which are caspase- 3 positive, could be an intermediary step between the still alive treated cells and the apoptotic dead cells. Caspase-3 positive staining, which allows to distinguish easily the atypical cells generated during the mitotic cell death process, is thus an interesting early marker of apoptosis, as already suggested by Hadjiloucas et al (2001).

There is still another possibility to explain the differences between the in vitro and in vivo results using small doses of BLM. Indeed, in the B16 tumours, no major change in the immune system infiltration was detected, while in the LPB tumours, after ECT with $10 \mu \mathrm{g}$ BLM, a massive infiltration of immune system cells was observed at the time points where a large fraction of apoptotic cells was also detectable $(25-100 \mathrm{~h}$ after the treatment). Interestingly, the percentage of apoptotic cells in LPB tumours was slightly higher than that in the B16F0 tumours. Of course, this could result from different kinetics in the generation and disappearance of the apoptotic cells in both tumours, but it cannot be excluded that the infiltrating immune system cells present in the LPB tumours at these time points could contribute to the generation of apoptotic cells. As a matter of fact, it is known that LPB cells are immunogeneic (Belehradek et al, 1972) while the B16F0 are not. In parallel, it must be noted that a large fraction (up to $60 \%$ ) of LPB tumours can be cured after one single ECT session using $10 \mu \mathrm{g}$ of BLM per mice (Mir et al, 1992) while, using exactly the same protocol, only $16 \%$ of the B16F0 tumours could be cured (Sersa et al, 1995). Moreover, the observation (Figure 2B) of the presence of a small fraction of mitotic B16F0 cells in the treated tumours (almost not detected in the LPB tumours) from $30 \mathrm{~h}$ on after the ECT is quite in line with the results of tumour cure. Thus, after the injection of a low BLM amount, the apoptosis detected in B16F0 tumours reinforces the suggestion that, in vivo, the final outcome of mitotic cell death is an apoptosis, in agreement with previous in vitro studies using ionising radiation (Tauchi and Sawada, 1994; Yanagihara et al, 1995). Simultaneously, our results also suggest that in LPB tumours the high fraction of apoptotic cells could result from the direct outcome of the treatment and the concomitant cytotoxic activity of the immune system.

In summary, using the high BLM dose, a pseudoapoptotic evolution of the tumour cells was found, reminiscent of the observation performed in vitro on cells electropermeabilised in the presence of high external BLM concentrations. Using the low dose, a cell death pathway like the one observed after tumour treatment by ionising irradiation (mitotic cell death) was observed shortly after the treatment. This cell death pathway ended through a real apoptotic process. The atypical caspase- 3 positive figures are an intermediary step in this process. Thus, antiactivated caspase- 3 staining is an early marker of apoptosis. Moreover, the difference in the results obtained in vivo with the high and low amounts of BLM can actually be interpreted, as in vitro, as the direct consequence of the number of BLM molecules internalised into the cells and, therefore, as the result of the number of DSB generated in these cells.

\section{ACKNOWLEDGEMENTS}

We are grateful to $\mathrm{R}$ Davalos for critical reading of the manuscript and linguistic revision of the manuscript. We are indebted to the technical staff of the department of pathology of the Institut Gustave-Roussy (IGR), and P Opolon and E Connault for their technical advises and Dominique Coulaud for help in electron microscopy. We also thank the staff of the Service Commun d'Expérimentation Animale of the IGR for animal maintenance, the CNRS (France) and DGRST (Tunisia) for travel support to OT and LMM for scientific exchanges. H Mekid was supported by a studentship from the Johnson and Johnson company and of the EU commission (project Cliniporator, QLK3-1999-00484). This work was essentially supported by the Centre National de la Recherche Scientifique (CNRS) and the IGR.

\section{REFERENCES}

Anderson ED, VanSlyke JK, Thulin CD, Jean F, Thomas G (1997) Activation of the furin endoprotease is a multiple-step process: requirements for acidification and internal propeptide cleavage. EMBO J 16: 1508 1518

Belehradek Jr J, Barski G, Thonier M (1972) Evolution of cell-mediated antitumor immunity in mice bearing a syngeneic chemically induced tumor. Influence of tumor growth, surgical removal and treatment with irradiated tumor cells. Int J Cancer 9: $461-469$

Chang WP, Little JB (1991) Delayed reproductive death in X-irradiated Chinese hamster ovary cells. Int J Radiat Biol 60: 483-496

Cohen-Jonathan E, Bernhard EJ, Mc Kenna WG (1999) How does radiation kill the cells? Curr Opin Chem Biol 3: 77-83

Dewey WC, Furman SC, Miller HH (1970) Comparison of lethality and chromosomal damage induced by X-rays in synchronized Chinese hamster cells in vitro. Radiat Res 43: $561-581$

Dini L, Coppola S, Ruzittu MT, Ghibelli L (1996) Multiple pathways for apoptotic nuclear fragmentation. Exp Cell Res 223: 340-347

Domenge C, Orlowski S, Luboinski B, de Baere T, Schwaab G, Belehradek Jr J, Mir LM (1996) Antitumor electrochemotherapy: new advances in the clinical protocol. Cancer 77: 956-963

Gehl J, Geertsen PF (2000) Efficient palliation of haemorrhaging malignant melanoma skin metastases by electrochemotherapy. Melanoma Res 10: $585-589$

Hadjiloucas I, Gilmore AP, Bundred NJ, Streuli CH (2001) Assessment of apoptosis in human breast tissue using an antibody against the active form of caspase-3: relation to tumour histopathological characteristics. Br J Cancer 85 (10): $1522-1526$

Joshi GP, Nelson WJ, Revell SH, Shaw CA (1982) X-ray-induced chromosome damage in live mammalian cells, and improved measurements of its effects on their colony-forming ability. Int J Radiat Biol Relat Stud Phys Chem Med 41: 161-181

Kerr JF, Searle J (1972) The digestion of cellular fragments within phagolysosomes in carcinoma cells. J Pathol 108: 55-58

Kolenko VM, Uzzo RG, Bukowski R, Finke JH (2000) Caspase-dependent and -independent death pathways in cancer therapy. Apoptosis 5: 17-20

Lew YS, Brown SL, Griffin RJ, Song CW, Kim JH (1999) Arsenic trioxide causes selective necrosis in solid murine tumors by vascular shutdown. Cancer Res 59: 6033-6037

Mekid H, Mir LM (2000) In vivo cell electrofusion. Biochim Biophys Acta 1524: $118-130$ 
Milross CG, Mason KA, Hunter NR, Chung WK, Peters LJ, Milas L (1996) Relationship of mitotic arrest and apoptosis to antitumor effect of paclitaxel. J Natl Cancer Inst 88: 1308 - 1314

Mir LM, Glass LF, Sersa G, Teissie J, Domenge C, Miklavcic D, Jaroszeski MJ, Orlowski S, Reintgen DS, Rudolf Z, Belehradek M, Gilbert R, Rols MP, Belehradek Jr J, Bachaud JM, DeConti R, Stabuc B, Cemazar M, Coninx P, Heller R (1998) Effective treatment of cutaneous and subcutaneous malignant tumours by electrochemotherapy. $\mathrm{Br} \mathrm{J}$ Cancer 77: $2336-2342$

Mir LM, Orlowski S, Belehradek Jr J, Paoletti C (1991) Electrochemotherapy potentiation of antitumour effect of bleomycin by local electric pulses. Eur J Cancer 27: 68-72

Mir LM, Orlowski S, Poddevin B, Belehradek Jr J (1992) Electrochemotherapy tumor treatment is improved by interleukin-2 stimulation of the host's defenses. Eur Cytokine Network 3: 331 - 334

Mir LM, Tounekti O, Orlowski S (1996) Bleomycin: revival of an old drug. Gen Pharmacol 27: $745-748$

Monti D, Troiano L, Tropea F, Grassilli E, Cossarizza A, Barozzi D, Pelloni MC, Tamassia MG, Bellomo G, Franceschi C (1992) Apoptosis programmed cell death: a role in the aging process? Am J Clin Nutr 55: $1208 \mathrm{~S}-1214 \mathrm{~S}$

Poddevin B, Orlowski S, Belehradek Jr J, Mir LM (1991) Very high cytotoxicity of bleomycin introduced into the cytosol of cells in culture. Biochem Pharmacol 42 (Suppl): S67-S75

Radford IR (1991) Mouse lymphoma cells that undergo interphase death show markedly increased sensitivity to radiation-induced DNA doublestrand breakage as compared with cells that undergo mitotic death. Int J Radiat Biol 59: 1353 - 1369

Rodriguez-Cuevas S, Barroso-Bravo S, Almanza-Estrada J, CristobalMartinez L, Gonzalez-Rodriguez E (2001) Electrochemotherapy in primary and metastatic skin tumors: phase II trial using intralesional bleomycin. Arch Med Res 32: 273-276

Rols MP, Tamzali Y, Teissie J (2002) Electrochemotherapy of horses. A preliminary clinical report. Bioelectrochemistry 55: $101-105$

Schwartz LM, Osborne BA (1993) Programmed cell death, apoptosis and killer genes. Immunol Today 14: 582-590

Sersa G, Cemazar M, Miklavcic D (1995) Antitumor effectiveness of electrochemotherapy with cis-diamminedichloroplatinum(II) in mice. Cancer Res 55: $3450-3455$

Sersa G, Cemazar M, Miklavcic D, Mir LM (1994) Electrochemotherapy: variable antitumor effect on different tumor models. Bioelectrochem Bioenerg 35: $23-27$
Shacter E, Williams JA, Hinson RM, Senturker S, Lee YJ (2000) Oxidative stress interferes with cancer chemotherapy: inhibition of lymphoma cell apoptosis and phagocytosis. Blood 96: 307-313

Shinomiya N, Kuno Y, Yamamoto F, Fukasawa M, Okumura A, Uefuji M, Rokutanda M (2000) Different mechanisms between premitotic apoptosis and postmitotic apoptosis in X-irradiated U937 cells. Int J Radiat Oncol Biol Phys 47: $767-777$

Tauchi H, Sawada S (1994) Analysis of mitotic cell death caused by radiation in mouse leukaemia L5178Y cells: apoptosis is the ultimate form of cell death following mitotic failure. Int J Radiat Biol 65: $449-455$

Tounekti O, Belehradek Jr J, Mir LM (1995) Relationships between DNA fragmentation, chromatin condensation, and changes in flow cytometry profiles detected during apoptosis. Exp Cell Res 217: 506-516

Tounekti O, Kenani A, Foray N, Orlowski S, Mir LM (2001) The ratio of single- to double-strand DNA breaks and their absolute values determine cell death pathway. Br J Cancer 84: $1272-1279$

Tounekti O, Pron G, Belehradek Jr J, Mir LM (1993) Bleomycin, an apoptosis-mimetic drug that induces two types of cell death depending on the number of molecules internalized. Cancer Res 53: 5462-5469

Trimmer EE, Essigmann JM (1999) Cisplatin. Essays Biochem 34: $191-211$

von Wangenheim KH, Peterson HP (1998) Control of cell proliferation by progress in differentiation: clues to mechanisms of aging, cancer causation and therapy. $J$ Theor Biol 193: 663-678

Workman P, Twentyman P, Balkwill F, Balmain A, Chaplin D, Double J, Embleton J, Newell D, Raymond R, Stables J, Stephens T, Wallace J (1998) United Kingdom Co-ordinating Committee on Cancer Research (UKCCCR) Guidelines for the Welfare of Animals in Experimental Neoplasia (Second Edition). Br J Cancer 77: 1-10

Wyllie AH, Kerr JF, Currie AR (1980) Cell death: the significance of apoptosis. Int Rev Cytol 68: 251-306

Wyllie AH, Morris RG, Smith AL, Dunlop D (1984) Chromatin cleavage in apoptosis: association with condensed chromatin morphology and dependence on macromolecular synthesis. J Pathol 142: $67-77$

Yanagihara K, Nii M, Numoto M, Kamiya K, Tauchi H, Sawada S, Seito T (1995) Radiation-induced apoptotic cell death in human gastric epithelial tumour cells; correlation between mitotic death and apoptosis. Int $J$ Radiat Biol 67: 677-685

Yoshida A, Ueda T, Wano Y, Nakamura T (1993) DNA damage and cell killing by camptothecin and its derivative in human leukemia HL-60 cells. Jpn J Cancer Res 84: 566-573 